\title{
Размеры выборок для информативного сравнения изрезанности листовой пластинки Populus nigra L. s.l. в условиях городских экосистем
}

\section{Sample sizes for informative comparison of Populus nigra L. s.l. leaf blade in urban ecosystems}

\author{
Штирц Ю. А. \\ Shtirts Yu. A. \\ Донеикий ботанический сад, г. Донеик, ДНР. E-mail: strelkova@i.ua \\ Donetsk Botanical Garden, Donetsk, DPR
}

\begin{abstract}
Peферат. Проведено определение минимальных размеров выборок, необходимых для информативного сравнения показателей изрезанности листовой пластинки Populus nigra L. s.l. в условиях городских экосистем. Материал собран в 2012-2017 гг. на территории г. Донецка с древесных растений зрелой стадии генеративного периода во время листопада. Для оценки степени изрезанности листовой пластинки применяли два различных подхода, ранее используемых исследователями. Минимальные размеры выборок, необходимые для информативного сравнения с использованием t-критерия Стьюдента показателя изрезанности как отношения периметра листовой пластинки к длине окружности, ограничивающей круг, площадь которого равна площади листовой пластинки, значительно ниже, чем для сравнения показателя изрезанности как отношения периметра листовой пластинки P. nigra к её площади.
\end{abstract}

Ключевые слова. Выборка, городские экосистемы, изрезанность, листовая пластинка, статистическая мощность, Populus nigra.

Summary. The determination of minimum sample sizes necessary for an informative comparison of Populus nig$r a$ L. s.l. leaf blade in urban ecosystems, taking into account statistical power, has been carried out. The material in 2012 2017 in territory of Donetsk with woody plants of mature stage of generative period during leaf fall was collected. To assess degree of leaf blade ruggedness two different approaches, previously used by researchers, were used. The minimum sample sizes required for informative comparison using Student's t-criterion ruggedness ratio as ratio of leaf blade perimeter to circumference circumscribing a circle whose area is equal to area of leaf blade are much lower than comparing the ruggedness ratio as ratio of leaf blade perimeter of $P$. nigra to its square.

Key words. Leaf blade, Populus nigra, ruggedness, sampling, statistical power, urban ecosystems.

\section{Введение}

Листовые пластинки многих видов растений обладают неровными краями. Функциональная значимость изрезанности листовой пластинки, причины возникновения и влияние факторов на степень проявления данного морфологического признака активно обсуждаются в различных литературных источниках.

Ряд исследователей указывают на существенную роль в формировании изрезанного края листа температурного фактора (Adams et al., 2008; Royer et al., 2009). Листья с изрезанными краями характеризуются большей способностью к теплоотдаче, чем листья с цельными краями (Gottschlich, Smith, 1982). Помимо влияния температурного фактора, адаптивную роль изрезанности листа D. L. Royer et al. (2012) связывают также с его толщиной. В работах T. J. Givnish $(1979,1984)$, T. J. Givnish, R. Kriebel (2017) указывается на существенное влияние на характер изрезанности листа особенностей расположения и строения жилок и толщины листовой пластинки. Приведены данные, согласно которым изрезанный край листа ряда видов растений играет важную роль в процессах фотосинтеза в начале периода вегетации (Baker-Brosh, Peet, 1997; Royer, Wilf, 2006). Существенна роль изрезанности 
листовой пластинки в процессах транспирации (Royer, Wilf, 2006) и гуттации (Feild et al., 2005). Более или менее рассеченные листья облегчают газообмен и теплоотдачу (Gates, 1968). Весомым фактором в формировании изрезанного края листа растений является доступность влаги. В условиях засоления почв уменьшается число видов, имеющих изрезанный край листовой пластинки, несмотря на достаточное количество влаги ввиду того, что солевой стресс вызывает физиологическую засуху (Royer et al., 2009). По мнению V. Brown, J. Lawton (1991), у некоторых видов растений изрезанность листа наряду с его размером и формой может быть эволюционным приспособлением, которое защищает от фитофагов. Существует точка зрения, согласно которой на изрезанность листовой пластинки влияет расположение примордиальных листьев внутри почки и особенности дальнейшего их роста внутри и вне почки (Couturier et al., 2012; Edwards et al., 2016).

Такая морфологическая особенность листа как изрезанность, по всей видимости, имеет различные причины возникновения в разных систематических группах и условиях произрастания, а также, вероятнее всего, возникла благодаря различным механизмам развития (Edwards et al., 2017).

Целью исследований являлось определение минимальных размеров выборок, необходимых для информативного сравнения показателей изрезанности листовой пластинки Populus nigra L. s.l. с учётом статистической мощности.

\section{Материал и методы}

Материал собран во время листопада в 2012-2017 гг. на территории г. Донецка с древесных растений зрелой стадии генеративного периода, произрастающих на территории городского парка и в условиях придорожных насаждений города с различной интенсивностью движения автотранспорта. Периоды листопада выбраны с целью рандомизации выборки. Определение возрастного состояния деревьев проводилось по системе О. В. Смирновой и др. (1976). Листья были отсканированы с разрешением 300 пикселей на дюйм.

Для оценки степени изрезанности листовой пластинки P. nigra использовали два подхода. В первом случае показатель изрезанности рассчитывали как отношение периметра листовой пластинки к длине окружности, ограничивающей круг, по площади равный площади листа. С этой целью использовалась программа Biological Pseudosymmetry (BioPS). Автоматический расчёт программой осуществляется следующим образом (Комплекс..., 2010).

Изначально площадь листа приравнивается к площади круга:

$S_{\pi}=S_{\mathrm{K}}=\pi R^{2}$,

где $S_{n}$ - площадь листовой пластинки, $S_{\kappa}$ - площадь круга, $R$ - радиус круга, по площади равного площади листовой пластинки.

Отсюда находится $R: \quad R=\sqrt{\frac{S_{\mathrm{K}}}{\pi}}$.

Длина окружности, ограничивающей круг, по площади равный площади листа, рассчитывается по формуле:

$$
L=2 \pi R=2 \pi \sqrt{\frac{S_{\mathrm{K}}}{\pi}} .
$$

Таким образом, степень изрезанности листа вычисляется как:

$$
I=\frac{P_{\pi}}{2 \pi \sqrt{\frac{S_{\mathrm{K}}}{\pi}}} .
$$

Описание расчёта данного показателя приведено в работе (Комплекс..., 2010). Изрезанность листа, рассчитанная с использованием программы BioPS, представляет собой безразмерную величину. В дальнейшем в тексте работы для удобства описания данный показатель приводится под названием «изрезанность как безразмерная величина». 
Во втором случае изрезанность листовой пластинки рассчитывали как отношение её периметра к площади (Sack et al., 2003; Крохмаль, 2014, 2016). В этом случае изрезанность измеряется в мм ${ }^{-1}$. В дальнейшем данный показатель приводится под названием «изрезанность, измеряемая в мм ${ }^{-1} »$. Площадь и периметр листовой пластинки, применяемые для проведения вычислений согласно этой формуле, также рассчитаны программой BioPS.

Таким образом, в вычислениях этих двух показателей изрезанности листовой пластинки реализованы различающиеся между собой логические подходы. В настоящее время оба показателя применяются в исследованиях (Sack et al., 2003; Крохмаль, 2014, 2016; Штирц, 2013, 2014, 2017).

Размеры выборок при проведении исследований значительно превышали рекомендуемые минимальные объёмы, установленные соответствующими вычислениями. Минимальные размеры выборок для определения информативных средних показателей рассчитывали согласно рекомендациям, приведенным в работе М. В. Козлова (2014), в частности, с использованием формулы вычисления объёма выборки из бесконечной генеральной совокупности. Минимальные размеры выборок для проведения информативного сравнения с учётом статистической мощности осуществлены по формулам, приведенным в работе M. Bland (2000).

\section{Результаты и обсуждение}

Изрезанность листовой пластинки P. nigra анализируемых выборок как безразмерная величина варьирует от 1,2174 до 1,7787; изрезанность, измеряемая в мм ${ }^{-1}$, варьирует от 0,0629 до 0,1933. Следует отметить, что в исследуемых выборках минимальные значения исследуемых показателей отмечены для одной и той же листовой пластинки. Листовая пластинка с максимальным значением показателя изрезанности как безразмерной величины имеет показатель изрезанности, измеряемой в мм $^{-1}$, равный 0,0933, с максимальным значением показателя изрезанности, измеряемой в мм ${ }^{-1},-$ показатель изрезанности как безразмерной величины, равный 1,5083.

Для визуального восприятия диапазона изменчивости изрезанности на рис. 1 отражены листовые пластинки с минимальными и максимальными значениями исследуемых показателей.
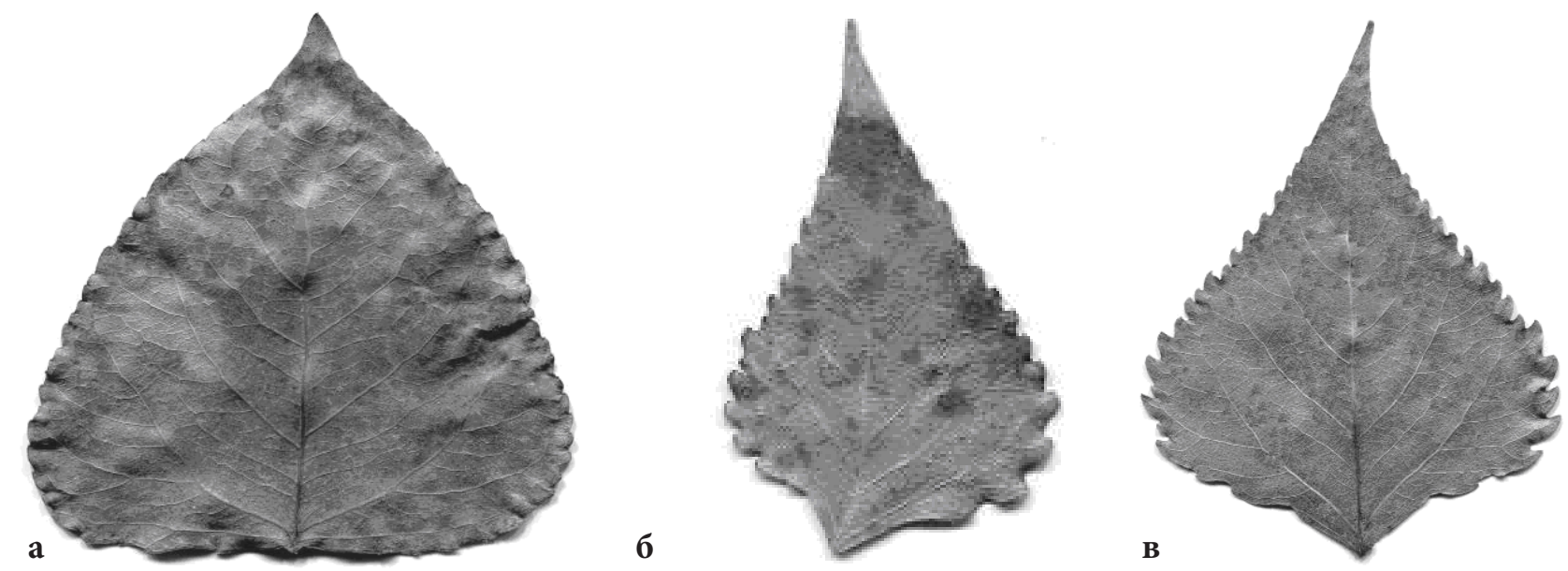

Рис. 1. Листовые пластинки Populus nigra L. s.l. с минимальными и максимальными значениями показателей изрезанности: а) с минимальными значениями двух анализируемых показателей изрезанности; б) с максимальным значением показателя изрезанности, измеряемой в мм $^{-1} ;$ в) с максимальным значением показателя изрезанности как безразмерной величины.

Минимальные размеры выборок для определения информативных средних показателя изрезанности листовой пластинки как безразмерной величины составили 8 листьев, показателя изрезанности, измеряемой в мм $^{-1},-100$ листьев.

Минимальные размеры выборок, необходимые для информативного сравнения с использованием t-критерия Стьюдента анализируемых показателей изрезанности листовой пластинки с учётом статистической мощности отражены в таблице. 
Минимальные размеры выборок, необходимые для информативного сравнения с использованием t-критерия Стьюдента показателей изрезанности листовой пластинки Populus nigra L. с учётом статистической мощности

\begin{tabular}{|c|c|c|c|c|c|c|}
\hline \multirow{2}{*}{$\begin{array}{c}\text { Показатель изрезанности листовой } \\
\text { пластинки }\end{array}$} & \multicolumn{4}{|c|}{ Статистическая мощность, \% } \\
\cline { 2 - 8 } & \multicolumn{2}{|c|}{$80 \%$} & \multicolumn{3}{c|}{$90 \%$} & \multicolumn{3}{c|}{$95 \%$} \\
\cline { 2 - 8 } & $\mathrm{P}=0,05$ & $\mathrm{P}=0,01$ & $\mathrm{P}=0,05$ & $\mathrm{P}=0,01$ & $\mathrm{P}=0,05$ & $\mathrm{P}=0,01$ \\
\hline $\begin{array}{c}\text { Изрезанность как безразмерная } \\
\text { величина }\end{array}$ & 19,54 & 29,16 & 26,17 & 37,14 & 32,31 & 44,40 \\
\hline \begin{tabular}{c} 
Изрезанность, измеряемая в мм ${ }^{-1}$ \\
\hline
\end{tabular} & 245,99 & 366,98 & 329,37 & 467,49 & 406,63 & 558,75 \\
\hline
\end{tabular}

Согласно данным таблицы, с целью сравнения изрезанности листовой пластинки, измеряемой в мм $^{-1}$, на $5 \%$ уровне значимости с $80 \%$ мощностью рекомендуемый минимальный размер выборки должен составить 246 листовых пластинок, в то время как указанный уровень статистической мощности при сравнении изрезанности как безразмерной величины достигается при объёме выборки 20 листовых пластинок, размер же выборки в 45 листьев позволяет выявить различия в значениях изрезанности как безразмерной величины на 1 \% уровне значимости с 95 \% мощностью.

Таким образом, минимальные размеры выборок, необходимые для информативного сравнения с использованием t-критерия Стьюдента показателя изрезанности листовой пластинки как безразмерной величины, значительно ниже, чем для сравнения показателя изрезанности, измеряемой в мм ${ }^{-1}$.

\section{ЛИТЕРАТУРА}

Козлов М. В. Планирование экологических исследований: теория и практические рекомендации. - М.: Товарищество научных изданий КМК, 2014. - 171 с.

Комплекс программных продуктов BioPS для автоматической количественной оценки степени псевдосимметрии растительных объектов), 2010. URL: http://ecograde.belozersky.msu.ru/links/index.html

Крохмаль И. И. Эколого-функциональная морфология листа видов рода Aquilegia L. // Ecology and noospherology, 2014. - Vol. 25, N 1-2. - P. 46-60.

Крохмаль I. I. Еколого-біологічні детермінанти успішності інтродукції трав `янистих багаторічників в степовій зоні України: автореф. дис. ... докт. біол. наук. - Київ, 2016. - 53 с.

Смирнова О. В., Заугольнова Л. Б., Таронова Н. А., Фаликов Л. Д. Критерии выделения возрастных состояний и особенности хода онтогенеза у растений различных биоморф // Ценопопуляции растений (основные понятия и структура). - М.: Наука, 1976. - Ч. І. - С. 14-43.

Штири Ю. А. Морфологическое разнообразие листовых пластинок Populus nigra L. в условиях промышленных отвалов // Промышленная ботаника: сб. науч. тр. - Донецк: Донецкий ботанический сад НАН Украины, 2013. - Вып. 13. - С. 116-124.

ШІшири Ю. $\boldsymbol{A}$. Морфологические параметры листовой пластинки Betula pendula Roth в условиях придорожных территорий автотранспортных магистралей г. Донецка // Інтродукція, збереження та моніторинг рослинного різноманіття: матер. Міжнар. наук. конф. (Київ, 20-24 травня 2014 р.). - Київ: ПАЛИВОДА А.В., 2014. - С. 217-218.

Штирц Ю. А. Изменчивость степени изрезанности края листовой пластинки Populus nigra L. в условиях промышленных отвалов // Acta Biologica Sibirica, 2017. - Vol. 3 (2). - P. 46-51.

Adams J. M., Green W. A., Zhang Y. Leaf margins and temperature in the North American flora: Recalibrating the paleoclimatic thermometer // Global and Planetary Change, 2008. - Vol. 60. - P. 523-534.

Baker-Brosh K. F., Peet R. K. The ecological significance of lobed and toothed leaves intemperate forest trees // Ecology, 1997. - Vol. 78 (4). - P. 1250-1255.

Bland M. An Introduction to Medical Statistics / 3rd. ed. - Oxford: Oxford University Press, 2000. - 405 p.

Brown V., Lawton J. Herbivory and the evolution of leaf size and shape // Philosophical Transactions of the Royal Society of London, B, Biological Sciences, 1991. - Vol. 333. - P. 265-272.

Couturier E., Brunel N., Douady S., Nakayama N. Abaxial growth and steric constraints guide leaf folding and shape in Acer pseudoplatanus // American Journal of Botany, 2012. - Vol. 99. - P. 1289-1299. 
Edwards E. J., Chatelet D. S., Spriggs E. L., Johnson E. S., Schlutius C., Donoghue M. J. Correlation, causation, and the evolution of leaf teeth: A reply to Givnish and Kriebel // American Journal of Botany, 2017. - Vol. 104 (4). P. 509-515.

Edwards E. J., Spriggs E. L., Chatelet D. S., Donoghue M. J. Unpacking a century-old mystery: Winter buds and the latitudinal gradient in leaf form // American Journal of Botany, 2016. - Vol. 103 (6). - P. 975-978.

Field T. S., Sage T. L., Czerniak C., Iles W. J. D. Hydathodal leaf teeth of Chloranthus japonicus (Chloranthaceae) prevent guttation-induced flooding of the mesophyll // Plant, Cell et Environment, 2005. - Vol. 28. - P. 1179-1190.

Gates D. M. Energy exchange and ecology // Bioscience, 1968. - Vol. 18. - P. 90-95.

Givnish T. $\boldsymbol{J}$. On the adaptive significance of leaf form / Topics in plant population biology. - New York: Columbia University Press, 1979. - P. 375-407.

Givnish T. J. Leaf and canopy adaptations in tropical forests // Physiological ecology of plants of the wet tropics, 1984. - P. 51-84.

Givnish T. J., Kriebel R. Causes of ecological gradients in leaf margin entirety: Evaluating the roles of biomechanics, hydraulics, vein geometry, and bud packing // American Journal of Botany, 2017. - Vol. 104. - P. 354-366.

Gottschlich D. E., Smith A. P. Convective heat transfer characteristics of toothed leaves // Oecologia, 1982. - Vol. 53, N 3. - P. 418-420.

Royer D. L., Kooyman R. M., Little S. A., Wilf P. Ecology of leaf teeth: A multi-site analysis from an Australian subtropical rainforest // American Journal of Botany, 2009. - Vol. 96. - P. 738-750.

Royer D. L., Peppe D. J., Wheeler E. A., Niinemets $\ddot{U}$. Roles of climate and functional traits in controlling toothed vs. untoothed leaf margins // American Journal of Botany, 2012. - Vol. 99. - P. 915-922.

Royer D. L., Wilf P. Why do toothed leaves correlate with cold climates? Gas exchange at leaf margins provides new insights into a classic paleotemperature proxy // International Journal of Plant Sciences, 2006. - Vol. 167. - P. 11-18.

Sack L., Cowan P. D., Jaikumar N., Holbrook N. M. The 'hydrology' of leaves: coordination of structure and function in temperate woody species // Plant, Cell et Environment, 2003. - Vol. 26. - P. 1343-1356. 